\title{
Studies on the Optimization and Storage Stability of Virgin Coconut Meal Incorporated Instant Sooji Halwa Mix
}

\author{
Mohammed Ayub Khan, Mahesh Chitrashekarachar, Anil Dutt Semwal*, Gopal Kumar Sharma \\ Defence Food Research Laboratory, Siddarthanagar, India. \\ Email: *adsemwal@yahoo.co.in
}

Received May $4^{\text {th }}, 2012$; revised June $1^{\text {st }}, 2012$; accepted June $8^{\text {th }}, 2012$

\begin{abstract}
Virgin Coconut Meal (VCM) was used for the development of instant wheat sooji (semolina) halwa mix with better nutritional attributes. Central composite rotatable design (CCRD) with 2 independent variables (sugar and VCM) and 4 responses (lightness, redness, taste and overall acceptability) was used for the optimisation. VCM incorporated instant halwa mix prepared using optimised levels of ingredients contained moisture $0.95 \%$; fat $26.2 \%$; protein $7.65 \%$; total ash $0.86 \%$; fibre $1.02 \%$ and received overall acceptability score of 8.5 on a 9 point hedonic scale providing $523.86 \mathrm{Kcal} /$ $100 \mathrm{~g}$. The changes in quality of stored VCM incorporated instant halwa mix packed in polypropylene (PP, $75 \mu)$ and laminates of metallised polyester (MP, $90 \mu$ ) were monitored in order to assess the shelf-life. Instant halwa mix remained stable and acceptable for one year in both the packaging materials under ambient temperature conditions $\left(15^{\circ} \mathrm{C}-\right.$ $34^{\circ} \mathrm{C}$ ). However, the rate of lipid peroxidation was found to be slightly higher in PP packed samples as compared to MP packed ones. Fatty acid composition of VCM incorporated instant halwa mix remained practically unchanged during storage. Oleic acid was the major fatty acid present in fat extracted from halwa mix followed by palmitic and lauric acids.
\end{abstract}

Keywords: Virgin Coconut Meal; Optimization; Packaging Materials; Shelf-Life; Overall Acceptability; Fatty Acid Composition

\section{Introduction}

Large quantity of wheat produced in India is utilized in the form of semolina for making sweet and savoury preparations. Wheat sooji (semolina) halwa is a highly popular product of Indian confectionary which is relished all over Indian sub-continent and prepared by roasting the semolina in vanaspati (hydrogenated fat) followed by addition of sugar and water. Instant halwa mix developed earlier [1] with a shelf-life of one year provided high convenience and required just 4 - 5 min heating in boiling water for reconstitution. It has been highly liked by Armed Forces and become popular among civilians as well.

Virgin coconut oil (VCO) is an emerging beneficial oil because of its various health benefits. It is extracted from fresh coconut kernels by mechanical or natural means under controlled temperature. The whitish residue left after the extraction of oil can be milled into flour named as Virgin Coconut Meal (VCM). As a source of dietary fibre VCM provides a number of health benefits in relation to coronary heart diseases, colon cancer and diabetics [2]. It has also been reported that consumption of high

${ }^{*}$ Corresponding author. fibre coconut meal products increased fecal bulk and lowered the serum cholesterol [3-5]. Usually, meal obtained after extraction of oil, found use in cattle, poultry and fish feed. However, oil extracted meal possess good nutritional properties which could be utilized for value addition in various processed foods. Yashi et al. [5] reported the process for the preparation of ready-to-eat Indian traditional sweet meal ladoo using VCM. Some workers [6-8] have also tried to extend the shelf-life of desiccated coconut powder based traditional Indian sweet products viz, Holige, Modaka, Burfi, but no data is available on the composition, method of preparation and packaging requirements of VCM based halwa mix. Therefore, attempts were made to prepare VCM incorporated instant halwa mix and evaluate its shelf-life.

\section{Materials and Methods}

\subsection{Raw Materials}

The basic ingredients like wheat sooji (semolina, 500 mesh size), vanaspati, sugar, cashew nuts and cardamom were procured from the local market at Mysore, Karnataka, India. Virgin coconut meal was supplied by Central Plantation Crops Research Institute (CPCRI), Kasargod, 
Kerala, India after the extraction of VCO. The VCM was powdered in an ultra centrifugal mill (Retsch R1, Haan, Germany) using 500 mesh sieve.

\subsection{Experimental Design}

A central composite rotatable design was used without any blocking. The number of points in the design was obtained on the basis of the number of independent variables (two) decided for the product. The parameters that influence the product quality and acceptability or functionality were taken as responses. The statistical software package Design Expert 7.02, Stat-Ease Inc. Minneapolis, USA was used to construct the experimental design as well as to analyse the data. Sugar powder and Virgin Coconut Meal (VCM) were taken as independent variable with lightness, redness of the processed product (as measured by Hunter colour), taste and Overall acceptability (OAA) scores on a 9 point hedonic scale (after reconstitution of instant halwa mix) were taken as responses. Since only two independent variables were involved the numbers of design points obtained were 13 including five centre point replications. The independent variables with their coded and actual values with range of levels are given in Table $\mathbf{1}$. The $\alpha$-values in the design outside the ranges were selected for rotatability of the design. The centre points were selected with ingredients at levels expected to yield satisfactory experimental results. Experimental runs were randomized in order to minimize the effect of unexpected variability in the observed responses

\subsection{Roasting of Wheat Sooji}

Required quantity of wheat sooji (semolina) was taken in a stainless steel vessel and continued heating with constant mixing till the temperature attained $130^{\circ} \mathrm{C}$. Once the required temperature was attained burner flame was put off and mixing continued till the roast temperature reached $60^{\circ} \mathrm{C}-70^{\circ} \mathrm{C}$.

\subsection{Preparation of Halwa Mix}

The different formulations obtained (Table 2) were weighed separately along with hydrogenated fat (vanaspati), fried cashewnut and cardamom powder and their weights were kept constant for all runs based on wheat sooji (semolina). Required quantity of vanaspati was

Table 1. Experimental range and levels of independent variables used in RSM in terms of actual and coded factors.

\begin{tabular}{cccccccc}
\hline \multirow{2}{*}{ Variables } & \multicolumn{9}{c}{ Range of levels } \\
\cline { 2 - 7 } & Actual & Coded & Actual & Coded & Actual & Coded \\
\hline Sugar powder (A) & 110 & -1 & 120 & 0 & 130 & +1 \\
VCM (B) & 10 & -1 & 20 & 0 & 30 & +1 \\
\hline
\end{tabular}

Table 2. Design of experiments for VCM incorporated instant sooji halwa.

\begin{tabular}{|c|c|c|c|c|c|c|}
\hline Run order & Sugar powder $(\mathrm{g})$ & VCM (g) & Lightness (L) & Redness (a) & Taste & OAA \\
\hline 1) & 135.0 & 20.0 & 30.4 & 7.9 & 8.1 & 8.1 \\
\hline 2) & 120.0 & 20.0 & 32.4 & 8.3 & 8.3 & 8.4 \\
\hline 3) & 120.0 & 5.90 & 34.0 & 6.4 & 6.5 & 6.4 \\
\hline 4) & 130.0 & 30.0 & 29.0 & 7.7 & 7.8 & 7.8 \\
\hline 5) & 106.0 & 20.0 & 31.5 & 7.5 & 7.5 & 7.4 \\
\hline 6) & 130.0 & 10.0 & 32.0 & 6.9 & 7.2 & 7.1 \\
\hline 7) & 120.0 & 34.0 & 28.7 & 7.7 & 7.9 & 7.9 \\
\hline 8) & 120.0 & 20.0 & 32.2 & 8.2 & 8.1 & 8.2 \\
\hline 9) & 120.0 & 20.0 & 32.1 & 8.4 & 8.5 & 8.6 \\
\hline 10) & 120.0 & 20.0 & 32.0 & 8.5 & 8.4 & 8.5 \\
\hline 11) & 110.0 & 30.0 & 29.5 & 7.4 & 7.7 & 7.6 \\
\hline 12) & 120.0 & 20.0 & 32.5 & 8.4 & 8.4 & 8.5 \\
\hline 13) & 110.0 & 10.0 & 33.0 & 6.7 & 6.8 & 6.8 \\
\hline
\end{tabular}


taken in a stainless steel vessel to which requisite quantities of pre roasted semolina (sooji) and virgin coconut meal were added and heating was continued till the temperature attained $152^{\circ} \mathrm{C}$. Once the required temperature was attained, the heating was discontinued and the mix allowed to cool to a temperature of $70^{\circ} \mathrm{C}-80^{\circ} \mathrm{C}$. Fried cashew nuts, required quantity of powdered sugar and cardamom were added and mixed thoroughly.

\subsection{Colour Measurement}

Different formulations of VCM incorporated instant halwa mix were evaluated for their colour values in terms of Lightness (L), redness (a) using a Hunter Colour Meter (Data Lab; Silvasa, Gujarat, India) with illuminant $\mathrm{D}_{65}$ and $10^{\circ}$ observers after calibrating the equipment using white and black standard ceramic tiles. Values of "L" indicated a brighter or whiter sample whereas "a" indicated red chromaticity.

\subsection{Reconstitution of Dry Mix}

$100 \mathrm{~g}$ of instant halwa mix was added to $130 \mathrm{ml}$ of boiling water and stirred continuously for 3 - 4 min until desired consistency was attained.

\subsection{Sensory Evaluation}

The sensory characteristics of rehydrated VCM incorporated halwa were evaluated by a panel of 15 semi trained judges by grading for taste and overall acceptability on a 9 point hedonic scale with 9 as excellent in all respects and 1 as unacceptable samples [9].

\subsection{Storage and Evaluation}

VCM incorporated instant halwa mix prepared by using optimized levels of ingredients was packed in polypropylene (PP, $75 \mu)$ and mettalised polyester (MP, $90 \mu)$ pouches $(10 \mathrm{~cm} \times 10 \mathrm{~cm})$, heat sealed and stored under ambient temperature $\left(15^{\circ} \mathrm{C}-35^{\circ} \mathrm{C}\right)$ conditions for further studies.

\subsection{Statistical Analysis}

Experiments were performed using a 2-way factorial design consisting of storage time and packaging materials as treatments. All the experiments were performed in triplicate and Analysis of Variance was calculated using Statistica Software Version 7.0 of Stat Soft Incorporation, Tulsa OK, USA [10].

\section{Analysis}

Moisture, protein, fat, total ash and total sugars were determined using standard AOAC methods [11]. Initially and at interval of three months, the changes in quality of
VCM incorporated instant halwa mix were monitored by determining peroxide value (PV) and free fatty acids (FFA) estimations as per AOCS methods [12], while thiobarbituric acid value (TBA) was determined according to the method of Tarledgis et al. [13]. Browning intensity in VCM incorporated instant halwa mix was determined by measuring the optical density of the alcoholic extract ( $5 \mathrm{~g}$ sample $+50 \mathrm{ml}, 70 \%$ alcohol, shake for $2 \mathrm{hr}$ ) at $420 \mathrm{~nm}$. Mineral content was determined using Atomic Absorption Spectrophotometer (Vario 6, Analytika Jena, Germany) as per the method of Khan et al. [14]. Fatty acid composition of fat extracted from halwa mix was determined using standard AOCS [12] (1990) method with the help of Gas Liquid Chromatograph (Chemito, HR 1000, Chennai, India) on a 10\% diethylene glycol-succinate column (DEGS, $\left.8 \times 1 / 8^{\prime \prime}\right)$ with nitrogen as carrier gas using flame ionization detector. During analysis, the column temperature was maintained at $190^{\circ} \mathrm{C}$ while the injector and detector temperatures were kept at $210^{\circ} \mathrm{C}$ and $230^{\circ} \mathrm{C}$ respectively.

Microbial profile of the VCM incorporated instant halwa mix samples was determined using the petri plate method as described by APHA [15] for standard plate count on agar, coliform count on violet red bile agar, faecal coliform on Escherichia coli agar and, yeast and mold counts on the potato dextrose agar. Presence of pathogens viz. coliform, salmonella and staphylococcus aureus was also determined using APHA methods [15].

\section{Results and Discussion}

VCM incorporated instant halwa mix was developed using RSM. The 13 experimental combinations of central composite rotatable design with two independent variables and responses studied have been given in Table 2 . The use of sensory scores like taste and overall acceptability as responses have been reported earlier [16]. Since colour values affect the overall acceptability of the finished product, these were also taken as response in the optimization of VCM incorporated instant halwa mix based on RSM. The ANOVA and the best fit polynomial models were obtained for all the responses (Table 3), to assess the suitability of model represented the data. The ANOVA for full second order regression model for different responses (Table 3) showed that the co-efficient of determination $\mathrm{R}^{2}$ was more than $80 \%$ and lack of fit (LoF) was insignificant indicating the fitness of polynomial models used for describing the effect of independent variables on the responses [17]. All the responses were equally influenced by the levels of sugar powder and VCM are visualized in the $3 \mathrm{D}$ surface plots. The effect of different variables on responses could be predicted using the following multiple regression equations (in terms of coded factors). 
Table 3. Co-efficients of second order polynomial regression models for the various responses.

\begin{tabular}{|c|c|c|c|c|}
\hline $\begin{array}{l}\text { Co-efficient } \\
\text { constant }\end{array}$ & Lightness (L) & Redness (a) & Taste & $\begin{array}{c}\text { Overall } \\
\text { acceptability }\end{array}$ \\
\hline \multicolumn{5}{|l|}{ Intercept } \\
\hline$\beta_{0}$ & 32.4 & 8.36 & 8.34 & 8.44 \\
\hline \multicolumn{5}{|l|}{ Linear } \\
\hline$\beta_{1}$ & $-0.38^{*}$ & $0.13^{*}$ & $0.17^{*}$ & $0.19^{*}$ \\
\hline$\beta_{2}$ & $-1.75^{*}$ & $0.42^{*}$ & $0.43^{*}$ & $0.045^{*}$ \\
\hline \multicolumn{5}{|l|}{ Quadratic } \\
\hline$\beta_{11}$ & $-0.71^{*}$ & $-0.22^{*}$ & $0.30^{*}$ & $-0.38^{*}$ \\
\hline$\beta_{22}$ & $-0.51^{*}$ & $-0.70^{*}$ & $0.60^{*}$ & $-0.68^{*}$ \\
\hline \multicolumn{5}{|l|}{ Interactive } \\
\hline$\beta_{12}$ & $0.12^{*}$ & $0.025^{*}$ & $0.075^{*}$ & $0.025^{*}$ \\
\hline$R^{2}$ & 0.974 & 0.985 & 0.965 & 0.0965 \\
\hline F-value & 53.22 & 95.45 & 38.76 & 39.52 \\
\hline Mean & 7.69 & 31.48 & 7.78 & 7.79 \\
\hline SD & 0.14 & 0.80 & 1.99 & 2.18 \\
\hline $\mathrm{CV} \%$ & 1.88 & 0.80 & 1.99 & 2.18 \\
\hline $\mathrm{LoF}$ & $\begin{array}{c}\text { Not } \\
\text { significant }\end{array}$ & $\begin{array}{c}\text { Not } \\
\text { significant }\end{array}$ & $\begin{array}{c}\text { Not } \\
\text { significant }\end{array}$ & $\begin{array}{c}\text { Not } \\
\text { significant }\end{array}$ \\
\hline
\end{tabular}

"Significant $(\mathrm{p} \leq 0.05)$.

$$
\begin{aligned}
& \text { Lightness of halwa mix }(\mathrm{Y})=32.4-0.38 * \mathrm{~A}-1.75 * \mathrm{~B} \\
& +0.12 * \mathrm{~A} * \mathrm{~B}-0.71 * \mathrm{~A}^{2}-0.51 * \mathrm{~B}^{2} \\
& \text { Redness of halwa mix }(\mathrm{Y})=8.36+0.13 * \mathrm{~A}+0.42 * \mathrm{~B} \\
& +0.025 * \mathrm{~A} * \mathrm{~B}-0.22 * \mathrm{~A}^{2}-0.70 * \mathrm{~B}^{2} \\
& \text { Taste of halwa mix }(\mathrm{Y})=8.34+0.17 * \mathrm{~A}+0.43 * \mathrm{~B} \\
& -0.075 * \mathrm{~A} * \mathrm{~B}-0.30 * \mathrm{~A}^{2}-0.60 * \mathrm{~B}^{2} \\
& \text { OAA of halwa mix }(\mathrm{Y})=8.44+0.19 * \mathrm{~A}+0.45 * \mathrm{~B} \\
& -0.025 * \mathrm{~A} * \mathrm{~B}-0.38 * \mathrm{~A} 2-0.68 * \mathrm{~B}^{2}
\end{aligned}
$$

Table 3 reveals that at linear and interactive levels, both sugar and VCM had a significant $(\mathrm{p} \leq 0.05)$ positive effect on the redness while at quadratic level both had significantly $(p \leq 0.05)$ negative effect while in case of lightness both had negative effect at linear level as well as qudratic levels. At the interactive level both sugar and VCM had a postive effect on the lightness. Similarly, sugar and VCM had a significant $(\mathrm{p} \leq 0.05)$ positive effect on taste and OAA at linear as well as quadractic levels, affecting significantly $(\mathrm{p} \leq 0.05)$ at interactive level. The effect of Sugar and VCM on lightness, redness, taste and OAA are shown in the Figures 1(a)-(c) and (d) respectively. All the responses were equally influenced by the levels of VCM and sugar. With the increase level of VCM and sugar, redness goes on increasing upti certain limit and tehn declined. The same trend follows in the case of taste and OAA of the VCM incorporated instant halwa mix. The response lightness was found to decrease with the increase in the levels of VCM and sugar.

\subsection{Optimisation of Independent Variables}

Optimisation of the variable levels was achieved by desirable maximization of the necessary responses along the fitted polynomial models by numerical optimisaiton procedure of design expert software. The solutions were sought to maximize the desirability funciton for the given criteria by being at random starting points. The best among them with a sutiable fit model was chosen as the optimised composition. The optimised recipe for the preparation of VCM incorporated fortified instant halwa mix was Sugar powder $122.36 \mathrm{~g}$, VCM $23.38 \mathrm{~g}$, hydrogenated fat $70 \mathrm{~g}$, cardamom powder $2 \mathrm{~g}$, cashewnuts $7 \mathrm{~g}$ based on $100 \mathrm{~g}$ of wheat sooji. The predictions for lightness, redness, taste and OAA were $31.4,8.43,8.43$ and 8.5 respectively with a desirability of 0.969 (Figure 2). The desirability graph for optimised levels of independent variables satisfying all responses has been represented in Figure 3. The validation of the predictions was done by actual observations recorded for lightness (31.6), redness (8.46), taste (8.4) and OAA (8.45). The measured responses were very much close to the predicted ones, reconfirming the adequacy of the models. Therefore, the optimised set of conditions was recommended for the preparation of VCM incorporated instant halwa mix.

\subsection{Storage Study of Optimised Sample}

Optimised VCM incorporated instant halwa mix had moisture, $0.95 \%$; protein $7.65 \%$; fat, $26.22 \%$; ash $0.86 \%$; fibre, $1.02 \%$ and carbohydrate $63.30 \%$ (by difference). The calorific value calculated from the above composition was found to be $523.86 \mathrm{Kcal} / 100 \mathrm{~g}$. VCM incorporated instant halwa mix could be reconstituted within 3 $4 \mathrm{~min}$ in boiling water irrespective of length of storage. The fatty acid profile of the fat extracted from halwa mix and the mineral composition have been given in Table 4 . Oleic acid (43.91\%) was the major fatty acid present, followed by palmitic $(39.03 \%)$ and lauric $(8.12 \%)$. The concentation of potassium (134 ppm) in VCM incorporated instant halwa mix was high, which may be attributed to a high level of potassium in coconut meal [18].

Chemical and sensory changes in VCM incorporated instant halwa mix during storage have been presented in Table 5. It is clear from the data that there were no significant changes in moisure content of instant halwa packed in both the packaging material upto 3 months and later decreased significantly $(p \leq 0.01)$ in both PP and MP packed samples. The role of packaging materials on the storage stability of VCM incorporated instant halwa 
Design-Expert? Software

Lightness

$\mathrm{X} 1=\mathrm{A}:$ Sugar
$\mathrm{X} 2=\mathrm{B}: \mathrm{VCM}$

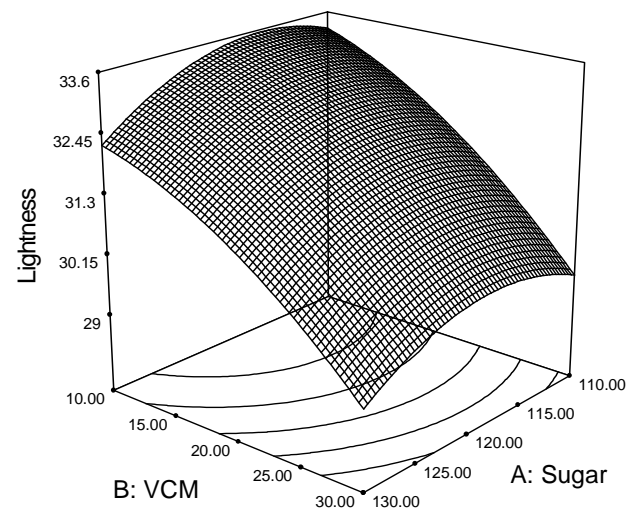

(a)

Design-Expert? Software

Taste

X1 = A: Suga X2 = B: VCM

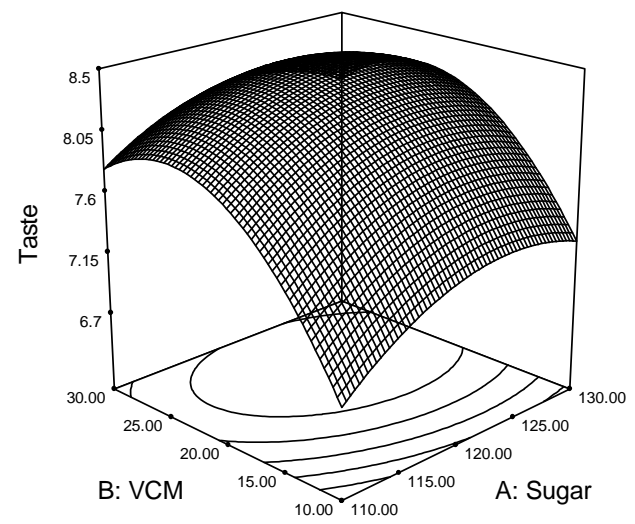

(c)
Design-Expert? Software

Redness

X1 = A: Sugar X2 = B: VCM

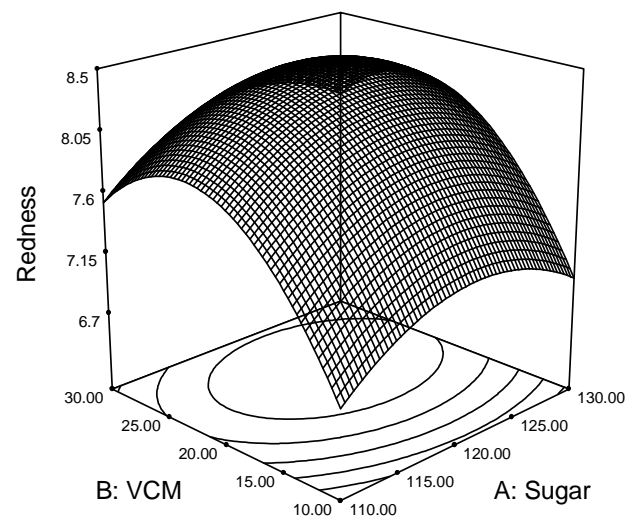

(b)

Design-Expert? Software

OAA

X1 $=$ A: Sugar
X2 $=$ B: VCM

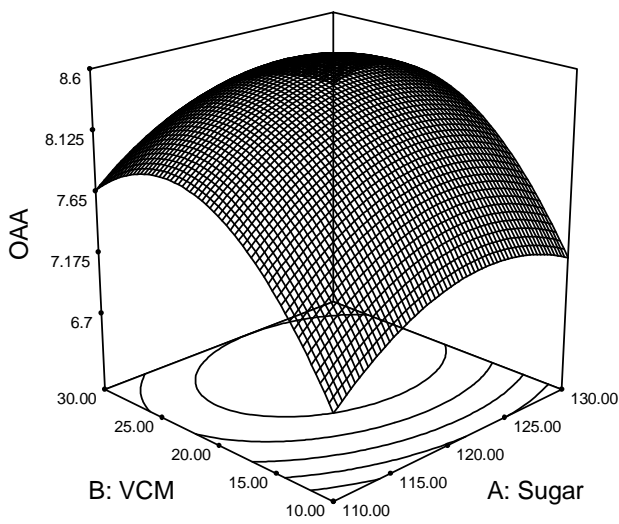

(d)

Figure 1. Effect of VCM and sugar on the lightness (a), redness (b), taste (c) and OAA (d) of VCM incorporated instant halwa mix.

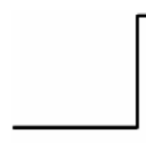

110.00

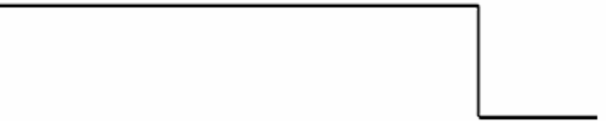

130.00

Sugar $=122.36$

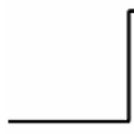

28.7

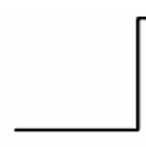

10.00

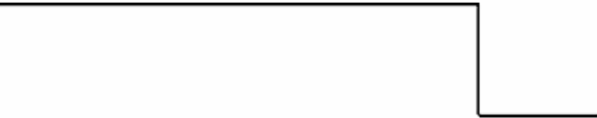

$\mathrm{VCM}=23.38$

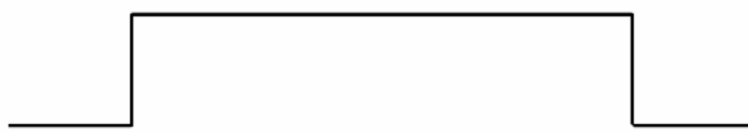

6.4

8.5

Redness $=8.43$

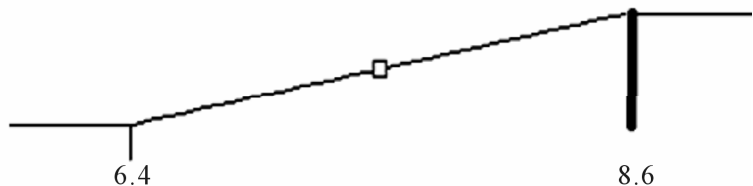

$\mathrm{OAA}=8.5$

Taste $=8.43$

8.5

Figure 2. Graphical representation of optimized levels of independent variables of VCM incorporated instant halwa mix. 
Table 4. Fatty acid (\%) and mineral composition (mg/100g) of instant halwa mix incorporated with VCM $(n=3)$.

\begin{tabular}{ccc}
\hline & \multicolumn{2}{c}{ Storage period (Months) } \\
\cline { 2 - 3 } Fatty acid Composition \\
Myristic & $4.26 \pm 0.02$ & $\mathrm{M}$ \\
Palmitic & $39.03 \pm 0.14$ & $39.11 \pm 0.02$ \\
Stearic & $2.89 \pm 0.04$ & $2.61 \pm 0.03$ \\
Oleic & $43.91 \pm 0.52$ & $44.01 \pm 0.50$ \\
Linoleic & $0.21 \pm 0.10$ & $0.19 \pm 0.10$ \\
Lauric & $8.12 \pm 0.09$ & $8.32 \pm 0.08$ \\
Capric & $1.02 \pm 0.01$ & $1.05 \pm 0.01$ \\
Caprylic & $0.56 \pm 0.05$ & $0.63 \pm 0.05$ \\
& Mineral composition \\
Calcium & $25.4 \pm 3.4$ & $24.8 \pm 2.8$ \\
Iron & $6.8 \pm 0.3$ & $6.6 \pm 0.4$ \\
Sodium & $53.2 \pm 4.3$ & $54.8 \pm 3.1$ \\
Potassium & $134.0 \pm 2.6$ & $136.2 \pm 2.9$ \\
Zinc & $1.9 \pm 0.10$ & $2.1 \pm 0.12$ \\
\hline
\end{tabular}

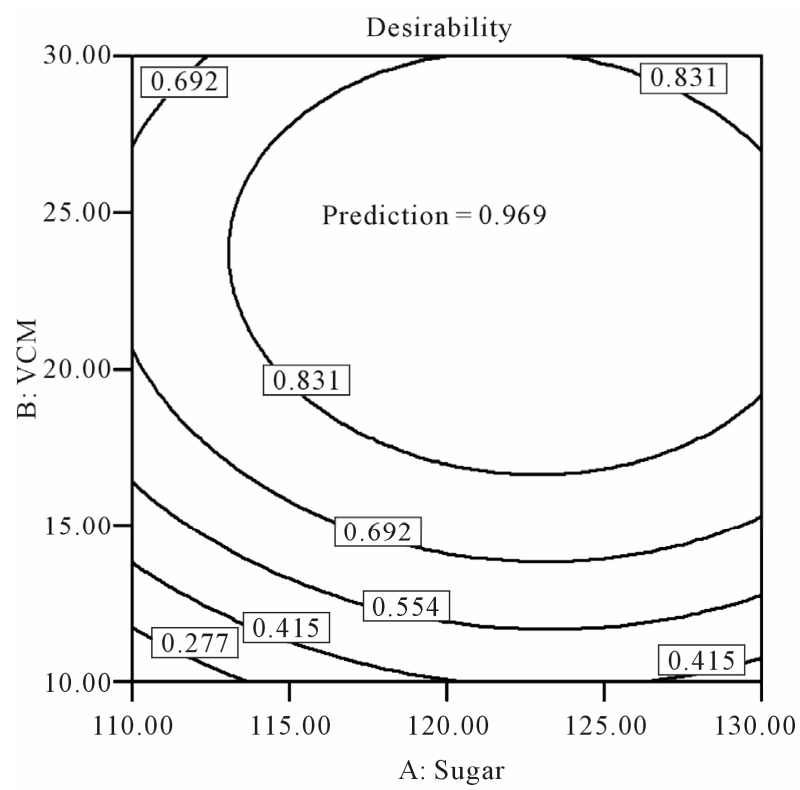

Figure 3. The desirability graph for optimised levels of independent variablesof VCM incorporated instant halwa mix.

mix under ambient temperture $\left(15^{\circ} \mathrm{C}-34^{\circ} \mathrm{C}\right)$ conditions was investigated on the basis of changes in peroxide value (PV), free fatty acid value (FFA), thiobarbituric acid value (TBA), browning index, taste colour and overall acceptability. It may be observed that the rate of autoxidation as measured by changes in PV and TBA values were siginificantly $(\mathrm{p} \leq 0.01)$ higher in samples packed in PP as compared to those in MP packed ones (Table 5). The peroxide value of VCM incorporated instant halwa mix packed in PP increased from 3.42 to $22.68 \mathrm{meqO}_{2} / \mathrm{kg}$ fat as compared to 3.42 to 18.48 meqO $/ 2$ kg for those packed in MP at the end of $12 \mathrm{~m}$ storage. The TBA values after $12 \mathrm{~m}$ of storage increased from 0.067 to 0.191 and 0.067 to $0.165 \mathrm{mg}$ malonaldehyde/kg in PP and MP packed samples respectively. FFA in instant halwa mix increased during storage irrespective of the packaging materials used and the increase was considerably higher in PP as compared to MP packed samples. After 12 months of storage, the FFA value in PP packed samples was 1.12 compared to 0.98 as \% oleic acid in MP packed ones. Hydrolysis of lipids during storage is normally brought about by the naturally occurring lipases [19]. However, during thermal processing employed for cooking and roasting, lipase activity was destroyed and therefore the formation of free fatty acids in stored VCM incorporated halwa mix must have resulted from the decomposition of hydroperoxide. Previously, Thakur \& Arya [20] have also reported an increase in FFA in the processed cereal products from the decomposition of hydroperoxide rather than that from lipids. In the present study, the samples having higher peroxide and TBA values were invariably found to have higher FFA suggesting the involvement of lipid autoxidation for an increase in FFA. There was no significant increase in the browning intensity and colour values in VCM incorporated instant halwa mix throughout the storage period.

There was practically no changes in the microbiological status of VCM incorporated instant halwa mix during the entire storage period. The total plate count of freshly prepared VCM incorporated instant halwa mix ranged between $75-100$ colonies $/ g$ and those of 12 months stored samples was $150-180$ colonies/g. Yeast and mold counts in fresh and stored samples were below $25 \mathrm{cfu} / \mathrm{g}$ and no coliform and fecal coliform were found in the stored halwa samples upto 12 months. The pathogens viz E. coli, S. aureus and salmonella were also absent in all the stored samples.

Changes in taste and overall acceptability scores of the reconstituted VCM incorporated instant halwa samples stored under ambient temperature conditions in PP and MP pouches have been shown in Table 5. Initially, the VCM incorporated instant halwa had an overall acceptability score of 8.5 on 9-point hedonic scale and therefore, a score of 7.0 was taken as limit for acceptability during the storage experiments. Based on the criteria, VCM incorporated instant halwa mix remained acceptable in both the packaging materials during the entire storage period of 12 months. However, acceptability of 
Table 5. Changes in moisture content (\%), peroxide value $\left(\mathrm{meqO}_{2} / \mathrm{kg}_{\mathrm{gat}}\right)$, free fatty acid value (FFA, \% oleic acid), thiobarbituric acid value (TBA, mg MA/Kg sample) and taste and overall acceptability score (OAA) of VCM incorporated halwa mix packed in Polypropylene (PP) and Metallised Polyester (MP) and stored under ambient temperature conditions (15 ${ }^{\circ} \mathrm{C}$ $\left.34^{\circ} \mathrm{C}\right)$.

\begin{tabular}{|c|c|c|c|c|c|c|c|c|c|c|c|c|}
\hline \multirow{2}{*}{$\begin{array}{l}\text { Storage } \\
\text { period } \\
\text { (months) }\end{array}$} & \multicolumn{2}{|c|}{ Moisture* } & \multicolumn{2}{|c|}{$\mathrm{PV}^{*}$} & \multicolumn{2}{|c|}{ FFA $^{*}$} & \multicolumn{2}{|c|}{$\mathrm{TBA}^{*}$} & \multicolumn{2}{|c|}{ Taste $^{* *}$} & \multicolumn{2}{|c|}{$\mathrm{OAA}^{* *}$} \\
\hline & PP & MP & PP & MP & PP & MP & PP & MP & PP & MP & PP & MP \\
\hline 0 & $0.95^{\mathrm{a}}$ & $0.95^{\mathrm{a}}$ & $3.42^{\mathrm{a}}$ & $3.42^{\mathrm{a}}$ & $0.42^{\mathrm{a}}$ & $0.42^{\mathrm{a}}$ & $0.067^{\mathrm{a}}$ & $0.067^{\mathrm{a}}$ & $8.5^{\mathrm{a}}$ & $8.5^{\mathrm{a}}$ & $8.5^{\mathrm{a}}$ & $8.5^{\mathrm{a}}$ \\
\hline 3 & $0.93^{\mathrm{a}}$ & 0.93 & $6.25^{\mathrm{bx}}$ & $5.88^{\mathrm{b}}$ & $0.69^{b x}$ & $0.64^{\mathrm{b}}$ & $0.086^{\text {bx }}$ & $0.081^{\mathrm{b}}$ & $8.2^{\mathrm{bx}}$ & $8.4^{\mathrm{b}}$ & $8.2^{\mathrm{bx}}$ & $8.4^{\mathrm{b}}$ \\
\hline 6 & $0.88^{\mathrm{bx}}$ & $0.90^{\mathrm{b}}$ & $10.35^{\mathrm{cx}}$ & $9.21^{\mathrm{c}}$ & $0.86^{\mathrm{cx}}$ & $0.78^{c}$ & $0.119^{\mathrm{cx}}$ & $0.107^{\mathrm{c}}$ & $7.8^{\mathrm{cx}}$ & $8.2^{\mathrm{c}}$ & $7.9^{\mathrm{cx}}$ & $8.2^{\mathrm{c}}$ \\
\hline 9 & $0.82^{\mathrm{cx}}$ & $0.87^{\mathrm{c}}$ & $16.84^{\mathrm{dx}}$ & $14.14^{d}$ & $0.92^{\mathrm{dx}}$ & $0.86^{\mathrm{d}}$ & $0.164^{\mathrm{dx}}$ & $0.148 \mathrm{~d}$ & $7.5^{\mathrm{dx}}$ & $7.9^{\mathrm{d}}$ & $7.3^{\mathrm{dx}}$ & $8.0^{\mathrm{d}}$ \\
\hline 12 & $0.77^{\mathrm{dx}}$ & $0.85^{\mathrm{d}}$ & $22.68^{\text {ex }}$ & $18.48^{\mathrm{e}}$ & $1.12^{\mathrm{ex}}$ & $0.98^{\mathrm{e}}$ & $0.191^{\mathrm{ex}}$ & $0.165^{\mathrm{e}}$ & $7.2^{\mathrm{ex}}$ & $7.4^{\mathrm{e}}$ & $7.1^{\mathrm{ex}}$ & $7.7^{\mathrm{e}}$ \\
\hline
\end{tabular}

${ }^{*}$ Mean $\pm \mathrm{SD}(\mathrm{n}=3) ;{ }^{* *}$ Mean $\pm \mathrm{SD}(\mathrm{n}=15) ;{ }^{\mathrm{a}-\mathrm{e}}$ Values within the same column with different superscripts differ significantly $(\mathrm{p} \leq 0.01) ;{ }^{\mathrm{x}}$ Significantly different from their corresponding PP packed samples $(\mathrm{p} \leq 0.01)$.

the product was higher in MP as compared to PP packed ones.

\section{Conclusion}

It is evident that highly acceptable VCM incorporated instant halwa mix capable of reconstitution in $3-4 \mathrm{~min}$ by putting in boiling water can be prepared. RSM was successfully utilized for optimization of the level of ingredients. Since, no rancid odour became perceptible during storage of VCM incorporated instant halwa mix upto 12 months under ambient temperature conditions, the autoxidation of lipids does not seem to be the critical factor in determining its shelf-life. Product can be stored in PP and MP packaging materials for more than 12 months under ambient temperature conditions $\left(15^{\circ} \mathrm{C}\right.$ $\left.34^{\circ} \mathrm{C}\right)$.

\section{REFERENCES}

[1] S. S. Arya and B. R. Thakur, "Instant Halwa (Kesari Bath) Mix-Storage Stability and Packaging Requirements," Indian Food Industry, Vol. 5, 1986, pp. 119-121.

[2] D. D. Bawalan, "The Economics of Production, Utilization and Marketing of Coconut Flour from Coconut Milk Residue," CORD, Vol. 14, No. 1, 2000, pp. 11-13.

[3] R. N. Arancon, "Coconut Flour," Cocoinfo International, Vol. 6, No. 1, 1999, pp. 8-10.

[4] K. D. P. P. Gunathilak and Y. M. R. K. Abeyrathne, "Incorporation of Coconut Flour into Wheat Flour Noodles and Evaluation of Its Rheological, Nutritional and Sensory Characteristics," Journal of Food Processing and Preservation, Vol. 32, No. 1, 2008, pp. 133-142. doi:10.1046/j.1439-0361.2003.02062.x

[5] Y. Srivatsava, A. D. Semwal, G. K. Sharma and A. S. Bawa, "Utilisation of Virgin Coconut Meal (VCM) in the Production of Ready-to-Eat Indian Traditional Sweet Meat Using Response Surface Methodology," Food and Nutrition Sciences, Vol. 2, No. 3, 2011, pp. 214-221.

\section{doi:10.4236/fns.2011.23029}

[6] T. S. Satyanarayana Rao, N. M. Kaverappa and K. S. Jayaraman, "Development of Shelf Stable Ready-to-Eat Indian Sweet Meats Based on Sugar and Coconut," Journal of Food Science and Technology, Vol. 27, No. 6, 1990, pp. 359-361.

[7] T. S. Satyanarayana Rao, N. M. Kaverappa and K. S. Jayaraman, "Development of Shelf Stable Ready-to-Eat Indian Sweet Meats Based on Jaggery and Coconut," Journal of Food Science and Technology, Vol. 27, 1999, pp. 355-358.

[8] V. Gupta, N. S. Vijayalakshmi, B. Ashwini, K. Anbarash, G. Vijayalakshmi, P. Maya, A. R. Indramma, G. C. P. R. Rao and B. R. Ramesh, "Shelf-Life Enhancement of Coconut Burfian Indian Traditional Sweet," Journal of Food Quality, Vol. 33, 2010, pp. 329-349. doi:10.1111/j.1745-4557.2010.00312.x

[9] E. Larmond, "Laboratory Methods for Sensory Evaluation of Food," Canada Department of Agriculture Publication, Ottawa, 1997, pp. 1637-1662.

[10] G. N. Snedecor and W. G. Cochran, "Statistical Methods," 6th Edition, Oxford and IBH Publication Company, New Delhi, 1968, pp. 234-257.

[11] Association of Official Analytical Chemists, "Methods of Analysis," 15th Edition, AOAC, Washington, 1990.

[12] American Oil Chemists Society, "Official Methods and Recommended Practices," 4th Edition, AOCS, Champaign, 1990.

[13] B. G. Tarledgis, B. M. Watts, M. E. Younathan and L. R. Dugon, "A Distillation Method for the Qualitative Determination of Malonaldehyde in Rancid Food," Journal of American Oil Chemists Society, Vol. 37, No. 1, 1960, pp. 44-47. doi:10.1007/BF02630824

[14] M. A. Khan, A .D. Semwal, G. K. Sharma, D. N. Yadav and K. A. Srihari, "Studies on the Development and Storage Stability of Groundnut (Arachis Hypogea) Burfi," Journal of Food Quality, Vol. 31, No. 5, 2008, pp. 612 626. doi:10.1111/i.1745-4557.2008.00224.x

[15] M. L. Speck, "Compendium of Methods for the Microbi- 
ological Examination of Foods," 2nd Edition, American Public Health Association, APHA, Washington, 1992.

[16] D. N. Yadav, G. K. Sharma and A. S. Bawa, "Optimisation of Soy Fortified Instant Sooji Halwa Mix Using Response Surface Methodology," Journal of Food Science and Technology, Vol. 44, 2007, pp. 297-300.

[17] R. G. Henika, "Use of Response Surface Methodology in Sensory Evaluation," Food Technology, Vol. 36, No. 11, 1982, pp. 96-101.

[18] C. Gopalan, B. V. R. Shastri and S. C. Balasubramanian,
"Nutritive Value of Indian Foods," National Institute of Nutrtion, Hyderabad, 1985.

[19] T. A. Clayton and W. R. Morrison, "Changes in Flour Lipids during Storage of Wheat Flour," Journal of Science of Food \& Agriculture, Vol. 23, No. 6, 1972, pp. 721-724. doi:10.1002/jsfa.2740230607

[20] B. R. Thakur and S. S. Arya, "Packaging Requirement and Stability of Fried Snacks (Trisnacks)," Journal of Food Science and Technology, Vol. 27, 1990, pp. 76-81. 